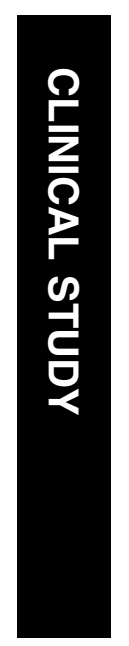

\title{
Effects of photodynamic therapy on subfoveal blood flow in neovascular age-related macular degeneration patients
}

${ }^{1}$ Department of Ophthalmology, University Hospital of Grenoble, Joseph Fourier University, Grenoble, France

${ }^{2}$ HES-SO Valais, Sion, Switzerland

${ }^{3} \mathrm{HP2}$ Laboratory, EA 3745 INSERM ERI 0017, Joseph Fourier University, Grenoble, France

Correspondence:

C Chiquet,

Department of

Ophthalmology,

University Hospital - CHU de Grenoble,

38043 Grenoble cedex 09, France

Tel: + 33 476768457;

Fax: + 33476765757

E-mail: cchiquet@

chu-grenoble.fr

Received: 13 May 2008 Accepted in revised form: 8 April 2009

Published online: 19 June 2009

\begin{abstract}
Aim To assess the short-term changes in choroidal blood flow (ChBF) after photodynamic therapy (PDT) in patients with neovascular age-related macular degeneration (AMD).

Methods Fourteen patients with exudative AMD were included after a complete ophthalmological examination, fluorescein and indocyanine green angiography and optical coherence tomography. Subfoveal ChBF was assessed using laser Doppler flowmetry (LDF) in both treated $(n=14)$ and nontreated contralateral $(n=8)$ eyes, $1 \mathrm{~h}$ and 1 week after PDT. Ocular perfusion pressure was calculated.

Results The detection sensitivity of the LDF measurements at 2-min intervals before PDT in treated eyes was $7.4 \%$ for volume, $6.3 \%$ for velocity, and $10.4 \%$ for ChBF. The initial mean visual acuity was $0.68 \pm 0.3 \log$ Mar. Macular thickness at baseline as measured by OCT3 was at median (interquartile range), $326.5 \mu \mathrm{m}$ (188-367). At $1 \mathrm{~h}$ and 7 days after PDT, a significant increase in velocity (15.8 and $24.4 \%$, respectively) and a significant decrease in volume (11 and $\mathbf{1 7 . 9 \%}$, respectively) were noted in treated eyes. Choroidal blood flow and ocular perfusion pressure (OPP) remained similar during follow-up. No significant change in flow parameters was reported in untreated eyes.

Conclusion The LDF technique provides feasible and reliable measurements of blood flow parameters before and after PDT in a selective population of patients with exudative AMD. The prognostic value of these
\end{abstract}

V Vinh Moreau-Gaudry', M Geiser², JP Romanet ${ }^{1}$, R Hera ${ }^{1}$, JY Millet ${ }^{1}$ and $C$ Chiquet $^{1,3}$ early blood flow parameter changes also needs to be assessed.

Eye (2010) 24, 706-712; doi:10.1038/eye.2009.130; published online 19 June 2009

Keywords: neovascular age-related macular degeneration; blood flow; laser Doppler flowmetry; photodynamic therapy

Introduction

Age-related macular degeneration (AMD) is the leading cause of legal blindness in people over the age of 65 in Western Europe and the USA. ${ }^{1}$ Owing to the development of choroidal neovascularization (CNV), the neovascular or exudative form leads to the most severe vision loss. Intravitreal injections of antivascular endothelial growth factor (anti-VEGF) are currently an approved standard treatment for neovascular AMD. This treatment modality can be combined with photodynamic therapy (PDT). PDT with verteporfin induces photothrombosis of the CNV without detectable damage to the overlying neurosensory retina. The beneficial effects of PDT have been shown in AMD in patients with predominantly classic and subfoveal occult progressing $\mathrm{CNV}^{2}$

Earlier histological studies in humans have underlined the selective destruction of vascular endothelial cells within the choriocapillary layer after PDT in AMD eyes., Moreover, collateral damage (that is, in healthy choriocapillaris and retinal pigment epithelium) after PDT has been reported in humans on angiography ${ }^{5}$ and histological analysis. ${ }^{4,6}$ The evaluation of in vivo choroidal blood flow (ChBF) variations after 
PDT in the area of neovascularization or of healthy choroid could help clinicians to quantify the vascular effects of PDT and thus improve the understanding of the mechanisms involved in this therapy.

The aim of this study was to evaluate the short-term ( $1 \mathrm{~h}$ and 7 days) post-PDT changes of the subfoveal ChBF in patients with neovascular AMD using the laser Doppler flowmetry (LDF) technique.

\section{Materials and methods}

Fourteen patients with exudative AMD treated with PDT in the Department of Ophthalmology of the University Hospital of Grenoble, France, were included in this prospective study between March 2006 and June 2007. This study was conducted in accordance with the Declaration of Helsinki for research involving human patients and the Good Clinical Practice guidelines. Informed consent was obtained from the patients after explanation of the study. The study protocol was approved by the local Institutional Review Board (Comité de Protection des Personnes, Sud-Est V).

Inclusion criteria included patient age over 50 years, clinically and angiographically proved exudative AMD requiring PDT treatment and patients with steady target fixation; visual acuity ranged from 0.3 to $1.3 \log$ Mar and the location of central fixation within the fovea was first verified at the time of fluorescein angiography (FA).

Patients with the following conditions were excluded from the study: eye of interest already treated with laser photocoagulation, PDT or anti-VEGF therapy, any evidence of disease that might interfere with the purpose of the trial (eg, ametropia >3 D, optic neuropathy, a concomitant retinal pathology), opaque ocular media (cataract, vitreous haemorrhage, corneal opacities), noncontrolled high blood pressure, intraocular surgery within the last 6 months, diabetes mellitus, cigarette smoking, and/or change in systemic or local medication during the follow-up period.

At the screening visit, the patients' history, including general and ocular history, weight, height and the intake of concomitant systemic drugs, was recorded (Table 1). A complete ophthalmologic examination with visual acuity (ETDRS), FA, and ICG angiography (ICGA, Topcon IMAGEnet, Clichy, France), optical coherence tomography (OCT 3, Zeiss, Oberkochen, Germany), and measurements of systemic blood pressure were carried out at inclusion. The neovascular lesions (location, size and subtypes) were characterized on the basis of both FA and ICGA (Table 1).

\section{Choroidal blood flow}

The LDF instrument used in this study to measure ChBF in the region behind the fovea has already been described

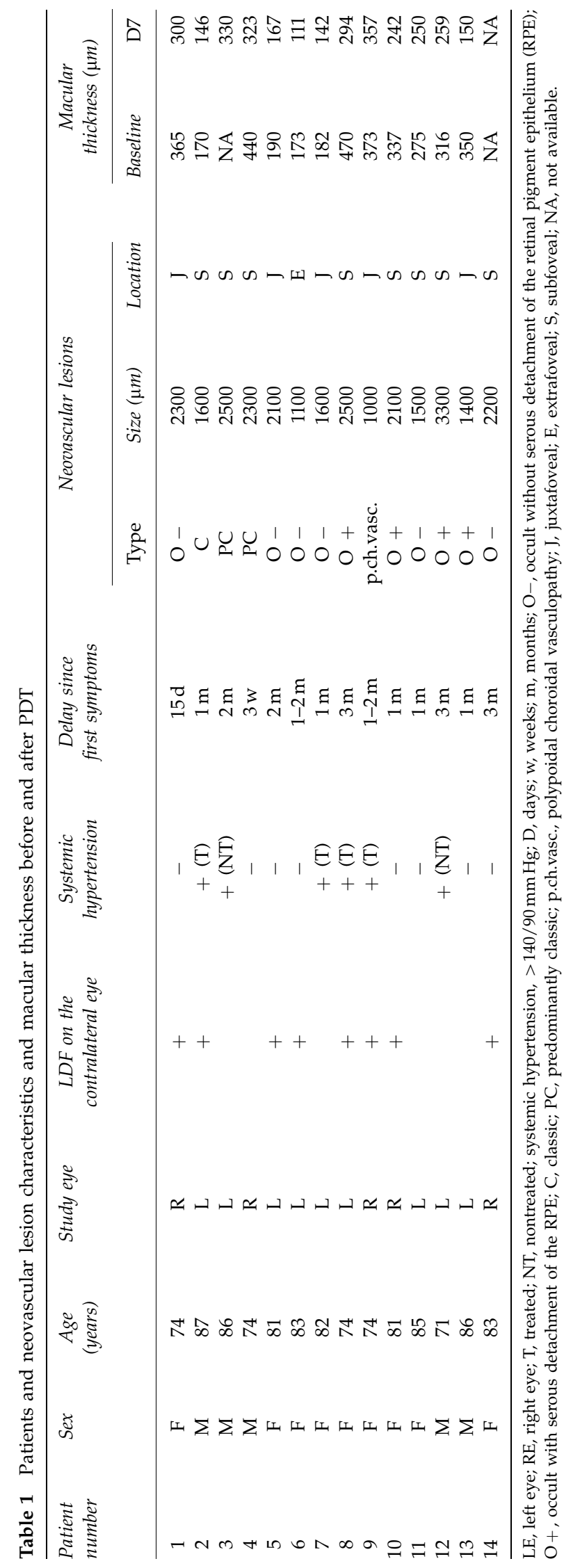


elsewhere, ${ }^{7}$ and we give here only a brief summary. It is based on the fact that reflected light on moving red blood cells (RBCs) will shift in frequency (Doppler effect). The instrument uses a coherent near-infrared probing beam (785 nm, $90 \mu \mathrm{W}$ at the cornea), which conforms to the American National Standards Institute (ANSI) Z 136.1 for laser safety. This instrument, which simplifies the alignment with the patient's eye, detects the light scattered by the RBCs within an annulus centred on the illumination site of the laser at the fovea. The illuminated laser spot and the detection annulus are self-aligned.

Light backscattered by the tissue in the sampled volume is collected by a bundle optical fibres and guided to an avalanche photodiode. The output photocurrent is sampled at a frequency of $240 \mathrm{kHz}$ with a 16-byte resolution and processed with Labview software (HESSO, Sion, Switzerland) on a PC computer to determine the $\mathrm{ChBF}$ parameters in real time at the rate of $17 \mathrm{~Hz} .^{8}$

Blood flow parameters are velocity, ChBVel (mean speed of RBCs, $\mathrm{kHz}$ ), volume, ChBVol (the number of moving RBCs in this volume, in arbitrary units, $\mathrm{AU}$ ), and the relative flow, $\mathrm{ChBF}=\mathrm{ChBVel} \times \mathrm{ChBVol}$ (in $\mathrm{AU}$ ), of the RBCs within the sampled tissue region. Assuming constant haematocrit levels, the changes in $\mathrm{ChBVol}$ and $\mathrm{ChBF}$ are proportional to the changes in actual volume and flow of blood, respectively.

The software automatically rejects signals for which the light intensity (DC: direct current) is not within $\pm 20 \%$ of its most frequent value, the LDF signal is absent or the volume is suddenly too large due to microsaccades, for example.

The flowmeter was mounted on a table equipped with a chin rest and head holder. Seated patients looked into the instrument, directly at the laser beam. The operator aligned the instrument in such a way that the DC signal reached a maximum, and care was taken to keep the DC signal as constant as possible during the recording. The intensity of the collected backscattered light or DC is a measurement of the optical properties of the local tissue under investigation. A change in that intensity would mean a change in the position of the probing beam and thus a change in the blood flow parameters. In that sense, the stability of the DC value is a sign of good reproducibility. Two or more continuous 30-s recordings of the choroidal circulation were obtained for each measurement. A minimum of $12 \mathrm{~s}$ of measurement was analysed in each eye.

\section{Protocol}

Patients were asked to abstain from alcohol and caffeine for at least $6 \mathrm{~h}$ before the trial. Before the LDF measurements, both pupils were dilated with $1 \%$ tropicamide and $10 \%$ phenylephrine (CIBA Vision
Ophthalmics, Blagnac, France). LDF was first carried out on nontreated eyes and then on treated eyes.

Photodynamic therapy is a two-step treatment. A photosensitizing drug (verteporfin, Visudyne, QLT, Vancouver, Canada; Novartis Ophthalmics, Bulach, Switzerland) is first intravenously administered to the patient at a dose of $6 \mathrm{mg} / \mathrm{m}^{2}$ for $10 \mathrm{~min}$. Fifteen minutes after the beginning of the infusion, a circular spot of nonthermal laser light $(689 \mathrm{~nm}$, Visulas $690 \mathrm{~s}$, Zeiss, Jena, Germany) of $50 \mathrm{~J} / \mathrm{cm}^{2}$ irradiating at an intensity of $600 \mathrm{~mW} / \mathrm{cm}^{2}$ is applied for $83 \mathrm{~s}$ through a slit lamp on the neovascular lesion with a $500-\mu \mathrm{m}$ circular safety margin added to the greatest linear dimension of the lesion.

The same experienced physician took all LDF measurements immediately before and after PDT ( $1 \mathrm{~h}$ and 7 days after). The laser wavelength was $785 \mathrm{~nm}$ and so is not likely to influence on the treatment effect, which occurs mainly at $400 \mathrm{~nm}$ and between 680 and $695 \mathrm{~nm}$. Verteporfin is not excited at $785 \mathrm{~nm} .{ }^{9}$ Immediately after blood flow measurements, systolic (BPsyst) and diastolic (BPdiast) blood pressures were determined (DINAMAP, Critikon, Inc., Tampa, FL, USA) and intraocular pressure (IOP) of the treated eye was measured by applanation tonometry (slit-lamp-mounted Goldmann tonometer, Haag-Streit, Bern, Switzerland) after instillation of one drop of oxybuprocaine hydrochloride (CIBA Vision Ophthalmics, Blagnac, France). The mean ocular perfusion pressure (OPP) was calculated according to the formula $\mathrm{OPP}=2 / 3 \mathrm{MAP}-\mathrm{IOP}^{10}{ }^{10}$ in which mean arterial pressure $(\mathrm{MAP})$ was calculated as $\mathrm{MAP}=\mathrm{BPdiast}+1 / 3$ (BPsyst-BPdiast).

All patients were examined before PDT, at $1 \mathrm{~h}(\mathrm{H} 1)$ and 7 days (D7) after treatment. At 1 week, best corrected visual acuity and macular thickness measurements using OCT3 were also assessed (software version 4.0.7, Carl Zeiss Meditec, Dublin, CA, USA; $n=12$, Table 1).

\section{Statistics}

Data at H1 and D7 were normalized based on baseline values. Changes in blood flow parameters and correlations were calculated using nonparametric tests (Friedman or Wilcoxon tests for paired comparisons) with SPSS 12.0 software (SPSS Inc. Headquarters, Chicago, IL, USA). All outcome variables were calculated for each patient individually and then averaged. Data are presented as mean \pm SEM. A two-tailed approach test determined the significance, which was set at $P<0.05$.

\section{Results}

\section{Patient characteristics}

The age of patients ranged from 71 to 87 years (median (interquartile range), 81.5 (74-84.5)); five patients were 

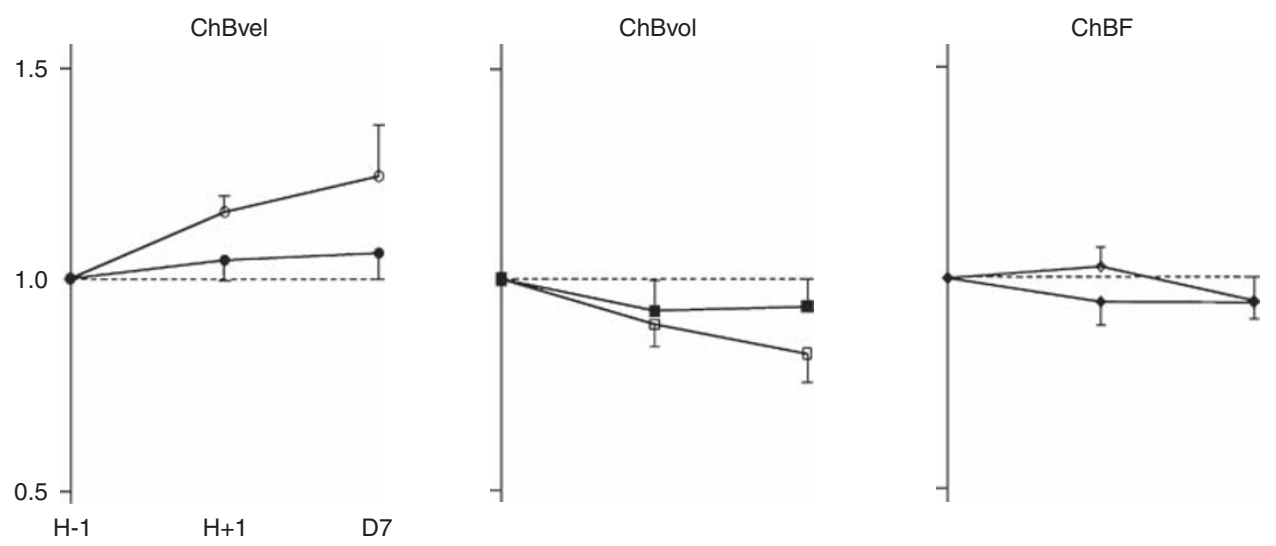

\begin{tabular}{|c|c|c|c|c|c|c|c|c|c|}
\hline \multirow{2}{*}{$\begin{array}{c}\text { Blood flow } \\
\text { parameters } \\
\text { (nonnormalized } \\
\text { values) }\end{array}$} & \multicolumn{3}{|c|}{ ChBVel (velocity) } & \multicolumn{3}{|c|}{ ChBVol (volume) } & \multicolumn{3}{|c|}{ ChBF (flow) } \\
\hline & $\mathrm{H}-1$ & $\mathrm{H}+1$ & D7 & $\mathrm{H}-1$ & $\mathrm{H}+1$ & D7 & $\mathrm{H}-1$ & $\mathrm{H}+1$ & D7 \\
\hline $\begin{array}{l}\text { Treated eyes } \\
\text { (mean } \pm \text { SEM) }\end{array}$ & $\begin{array}{c}3028 \\
\pm 303.7\end{array}$ & $\begin{array}{c}3458 \\
\pm 324.6\end{array}$ & $\begin{array}{r}3620 \\
\pm 347.8\end{array}$ & $\begin{array}{r}6.66 \\
\pm 0.39\end{array}$ & $\begin{array}{r}6.08 \\
\pm 0.63\end{array}$ & $\begin{array}{r}5.42 \\
\pm 0.56\end{array}$ & $\begin{array}{c}0.18 \\
\pm 0.018\end{array}$ & $\begin{array}{r}0.19 \\
\pm 0.02\end{array}$ & $\begin{array}{r}0.17 \\
\pm 0.02\end{array}$ \\
\hline $\begin{array}{c}\text { Nontreated eyes } \\
\text { (mean } \pm \text { SEM) }\end{array}$ & $\begin{array}{c}2956 \\
\pm 209.6\end{array}$ & $\begin{array}{c}3056 \\
\pm 226.5\end{array}$ & $\begin{array}{r}3047 \\
\pm 194.6\end{array}$ & $\begin{array}{r}7.17 \\
\pm 0.49\end{array}$ & $\begin{array}{r}6.39 \\
\pm 0.27\end{array}$ & $\begin{array}{r}6.46 \\
\pm 0.38\end{array}$ & $\begin{array}{r}0.20 \\
\pm 0.02\end{array}$ & $\begin{array}{r}0.18 \\
\pm 0.02\end{array}$ & $\begin{array}{r}0.19 \\
\pm 0.02\end{array}$ \\
\hline
\end{tabular}

Figure 1 Mean normalized variations (mean \pm SEM) of blood flow parameters in treated eyes (white) and nontreated eyes (black), $1 \mathrm{~h}$ and 7 days after photodynamic therapy. In treated eyes, ChBVel increased significantly $1 \mathrm{~h}(P=0.009)$ and 7 days $(P=0.02)$ after PDT, and ChBVol decreased significantly $1 \mathrm{~h}(P=0.03)$ and 7 days $(P=0.02)$ after PDT. ChBF did not vary significantly after PDT. In nontreated eyes, blood-flow parameters did not change significantly.

men and nine women. The patients' characteristics are summarized in Table 1. Four out of six hypertensive patients were receiving antihypertensive therapy (two took $\beta$-blockers, two took diuretics, one took calcium channel blockers and three took angiotensin receptor blockers). These drugs have not been modified during the study. All patients reported a well-balanced diet.

The patients' ocular history is specified in Table 1 . The study eye was the first eye affected by exudative AMD for 10 patients. All patients had a steady fixation in the treated eye. The study of the nontreated eye was not possible for six patients because of the lack of fixation due to cataract (\#3), and a history of retinal detachment with low vision (\#12) or central scotoma secondary to an earlier exudative AMD lesion (\#4, 6, 11 and 13).

According to the AREDS simplified severity scale, 11 nontreated eyes had both drusen $125 \mu \mathrm{m}$, and higher and pigmentary abnormalities, whereas three had only one of these lesions.

\section{LDF measurements in nontreated eyes}

Eight nontreated eyes were considered for LDF measurements. Average DC values did not vary significantly (4\% at $1 \mathrm{~h}$ (H1) and $2 \%$ at 7 days (D7), $P=0.4$ ) as compared with baseline. Blood flow parameters (ChBVel, ChBVol and ChBF) showed no statistically significant difference at $\mathrm{H} 1$ and D7, when compared with baseline values $(P>0.4)$. Mean normalized variations over time are illustrated in Figure 1.

\section{LDF measurements in treated eyes}

The detection sensitivity (S) of the LDF measurements was calculated before PDT based on two measurements taken 2 min apart. $S$ was defined $\operatorname{as}^{7} S=(\mathrm{SD} / \bar{m}) \cdot(t / \sqrt{n})$ in which $n=14$ is the number of patients, SD is the standard deviation of the difference between the first (baseline) and second measurements (at H1), $m$ the mean value of all measurements, and $t$ the two-tail value of the $t$ distribution at a 0.05 significance level for $n-1 . S$ was 7.4\% for ChBVol, $6.3 \%$ for $\mathrm{ChBVel}$, and $10.4 \%$ for ChBF.

Direct current values did not vary significantly between visits ( $6 \%$ at $\mathrm{H} 1,2 \%$ at $\mathrm{D} 7, P=0.13)$, whereas velocity $(P=0.004)$ and volume $(P=0.003)$ values were significantly different between the three visits. In contrast, flow values remained stable $(P=0.06)$.

Recordings carried out $1 \mathrm{~h}$ (Figure 1) after PDT showed a statistically significant rise in mean $\mathrm{ChBVel}$ of $15.8 \%$ $(P=0.009)$ and a significant reduction in $\mathrm{ChBVol}$ of $11 \%$ $(P=0.03)$. ChBF did not vary significantly (variation of $2.7 \%, P=0.8$ ). 
One week after PDT (Figure 1), a significant increase in mean $\mathrm{ChBVel}$ of $24.4 \%(P=0.02)$ and a significant decrease in mean ChBVol of $17.9 \%(P=0.02)$ were noted, whereas ChBF remained constant $(P=0.08)$.

\section{Blood pressure, intraocular pressure, and mean ocular perfusion pressure}

No statistically significant changes in MAP $(P=0.3)$, IOP $(P=0.57)$ and OPP $(P=0.67)$ were noted between preand post-PDT measurements.

\section{Visual acuity and OCT}

At 1 week, visual acuity was stable for all patients $(0.68 \pm 0.3 \log$ MAR at baseline $v s 0.69 \pm 0.3$ at D7, $P=0.8)$ and the patients retained proper fixation checked by a stable backscattered light (DC). The amount and localization of retinal haemorrhages within the macula did not change between D7 and the baseline visit.

Macular thickness as measured by OCT3 decreased significantly between baseline and D7 (median (interquartile range), 326.5 (188-367) vs 250 (150-300), $P=0.002$, Table 1).

\section{Discussion}

Our results showed that PDT induced a significant increase in choroidal velocity and a significant decrease in choroidal volume within 7 days. This reduction in volume may be consistent with a subfoveal choriocapillaris closure. Modifications of ChBF velocity and volume lead to a stability of ChBF after PDT.

This study also showed the feasibility of ChBF measurements before and after one session of PDT for subfoveal and juxtafoveal neovascularization in AMD eyes. Macular blood flow variations in patients with age-related macular degeneration after PDT and transpupillary thermotherapy have already been described, but using a Heidelberg scanning device (Heidelberg retinal Flowmeter, Heidelberg Engineering $\mathrm{GmbH}$, Heidelberg, Germany). ${ }^{11}$ The interpretation of the measurements carried out with this device may be difficult as the highest frequency obtained reaches about $2 \mathrm{kHz}$, whereas ChBVel may exceed $10 \mathrm{kHz}$.

The LDF technique was used in this study because of its noninvasiveness, the short-lasting measurements, which facilitate recordings in elderly patients, and the reported reproducibility and sensitivity in healthy ${ }^{12-14}$ and AMD eyes. ${ }^{15-20}$ Great care was taken to keep the DC as constant as possible during the recordings, which is necessary for valuable comparisons of $\mathrm{ChBF}$ parameters in a given patient. ${ }^{12}$ The sensitivity of the LDF measurements in AMD eyes of this study was consistent with that described in healthy eyes using the same device. ${ }^{7,13,14}$ The calculation of the sensitivity is bound to an experience and not to the instrument. It gives the minimum variation of a parameter that is statistically significant in response to a given stimulus (PDT in this experiment) for a given population of patients. Another methodological consideration is with regard to BP treatment, which may have an effect on ChBF. No major effect of antihypertensive treatment could be expected on ChBF before and after PDT as the drugs have not been modified during the study.

The lack of significant variations of ChBF parameters in nontreated eyes suggested that ChBVol and ChBVel changes in the treated eyes assessed in this study are mostly induced by PDT and not linked to physiological variations of ChBF parameters.

The follow-up schedule chosen in this study (LDF measurements within the first week) was based on earlier angiographic and histological studies of PDT reporting early modifications occurring within the first week after PDT. $^{4-6,21}$ Furthermore, PDT itself may influence tissue scattering by inducing modifications of the choriocapillaris and the tissues around the neovascular lesion (ie, atrophic, fibrotic, and/or haemorrhagic changes). Hence we stopped our experiment at 1 week after treatment to reduce any bias associated with tissuescattering property changes. This bias cannot be ruled out in this study at D7 since we found at this time, as others have, ${ }^{22,23}$ morphological macular changes such as a significant reduction of macular oedema in OCT3. However, we report no change in retinal haemorrhages during the 1-week follow-up.

The decrease in ChBVol observed in our study, especially at D7, may be explained by the selective destruction of the choriocapillary layer and the CNV closure. The reduced volume found using our LDF device, which measures to a depth of $300 \mu \mathrm{m},{ }^{24}$ may include the zone of the neovascular lesion and healthy choriocapillaris with vacuolization, shrinkage and fragmentation of endothelial cells, and detachment from their basement membrane detected as early as $24 \mathrm{~h}$ after PDT, both in animal models ${ }^{6}$ and in humans. ${ }^{4}$

The stability of blood flow was relative to the rise in velocity and decrease in volume. Indeed, in a constricted or restricted vascular bed (as occurs at the time of PDTinduced thrombosis), the erythrocytes may only move faster through the vessel with no decrease in the total number of erythrocytes passing through the choriocapillaris. Velocity changes may also be related to the regulation mechanisms ${ }^{15}$ of choroidal blood circulation in healthy choroid and/or in CNV tissue. These blood flow variations should be further studied with modified fluences of PDT.

In the case of hypoperfusion induced by choriocapillary layer occlusion secondary to PDT 
treatment, many biochemical changes may influence blood-cell velocity, such as released reactive oxygen intermediates attributable to hypoxia and/or oxidative stress. A recent publication has reported that VEGF enhances the formation of nitric oxide (NO, vasodilator) in cultured choroidal cells. ${ }^{25} \mathrm{NO}$ is known to be an important mediator of endothelial function that influences vascular tone, platelet aggregation, endothelial cell permeability, and vascular proliferation. As VEGF is produced after $\mathrm{PDT}^{26}$ and $\mathrm{NO}$ is known to be a regulator of $\mathrm{ChBF}_{,}^{27,28}$ further studies are needed to explore the role of $\mathrm{NO}$ in neovascular lesions before and after treatment.

In conclusion, the laser Doppler technique provides feasible and reproducible measurements of blood flow parameters before and after PDT in a selected population of patients with exudative AMD. This study also shows that ChBF parameters vary as early as $1 \mathrm{~h}$ after PDT with a significant rise in $\mathrm{ChBVel}$, a significant reduction in ChBVol, but with no significant change in ChBF. These changes correlated well with those described in histological studies. In patients without appropriate fixation, the analysis of the $\mathrm{ChBF}$ will require LDF measurements with a video follow-up of the fundus. The prognostic value of these early blood-flow parameter changes needs to be further assessed.

\section{Acknowledgements}

This study was supported by a grant from University Hospital of Grenoble, France (CHU de Grenoble, Innovations Hospitalières 2005).

\section{References}

1 Buch H, Nielsen NV, Vinding T, Jensen GB, Prause JU, la Cour M. 14-year incidence, progression, and visual morbidity of age-related maculopathy: the Copenhagen City Eye Study. Ophthalmology 2005; 112(5): 787-798.

2 Smith BT, Joseph DP, Grand MG. Treatment of neovascular age-related macular degeneration: past, present and future directions. Curr Opin Ophthalmol (Review) 2007; 18(3): 240-244.

3 Gelisken F, Lafaut BA, Inhoffen W, Voelker M, Grisanti S, Bartz-Schmidt KU. Clinicopathological findings of choroidal neovascularisation following verteporfin photodynamic therapy. Br J Ophthalmol 2004; 88(2): 207-211.

4 Schmidt-Erfurth U, Laqua H, Schlotzer-Schrehard U, Viestenz A, Naumann GO. Histopathological changes following photodynamic therapy in human eyes. Arch Ophthalmol 2002; 120(6): 835-844.

5 Michels S, Schmidt-Erfurth U. Sequence of early vascular events after photodynamic therapy. Invest Ophthalmol Vis Sci 2003; 44(5): 2147-2154.

6 Husain D, Kramer M, Kenny AG, Michaud N, Flotte TJ, Gragoudas ES et al. Effects of photodynamic therapy using verteporfin on experimental choroidal neovascularization and normal retina and choroid up to 7 weeks after treatment. Invest Ophthalmol Vis Sci 1999; 40(10): 2322-2331.

7 Geiser M, U Diermann, Riva CE. Compact laser Doppler choroidal flowmeter. J Biomed Opt 1999; 4(4): 459-464.

8 Bonner RF, Nossal R. Principles of laser doppler flowmetry. In: Shepherd AP, Öberg PA (eds). Developments in Cardiovascular Medicine: Laser Doppler Blood Flowmetry. Kluwer Academic Publishers: Boston, 1990, pp 73-92.

9 Aveline B, Hasan T, Redmond RW. Photophysical and photosensitizing properties of benzoporphyrin derivative monoacid ring A (BPD-MA). Photochem Photobiol 1994; 59(3): 328-335.

10 Bill A, Nilsson SF. Control of ocular blood flow. J Cardiovasc Pharmacol 1985; 7(Suppl 3): S96-S102. (review).

11 Kubicka-Trzaska A. Macular microcirculation blood flow in patients with age related macular degeneration treated with photodynamic therapy and transpupillary thermotherapy. Klin Oczna 2007; 109(4-6): 138-141.

12 Gugleta K, Orgul S, Flammer I, Gherghel D, Flammer J. Reliability of confocal choroidal laser Doppler flowmetry. Invest Ophthalmol Vis Sci 2002; 43(3): 723-728.

13 Lovasik JV, Kergoat H, Riva CE, Petrig BL, Geiser M. Choroidal blood flow during exercise-induced changes in the ocular perfusion pressure. Invest Ophthalmol Vis Sci 2003; 44(5): 2126-2132.

14 Longo A, Geiser MH, Riva CE. Posture changes and subfoveal choroidal blood flow. Invest Ophthalmol Vis Sci 2004; 45(2): 546-551.

15 Pournaras CJ, Logean E, Riva CE, Petrig BL, Chamot SR, Coscas $\mathrm{G}$ et al. Regulation of subfoveal choroidal blood flow in age-related macular degeneration. Invest Ophthalmol Vis Sci 2006; 47(4): 1581-1586.

16 Figueroa M, Schocket LS, DuPont J, Metelitsina TI, Grunwald JE. Long-term effect of laser treatment for dry age-related macular degeneration on choroidal hemodynamics. Am J Ophthalmol 2006; 141(5): 863-867.

17 Grunwald JE, Hariprasad SM, DuPont J, Maguire MG, Fine $\mathrm{SL}$, Brucker AJ et al. Foveolar choroidal blood flow in agerelated macular degeneration. Invest Ophthalmol Vis Sci 1998; 39(2): 385-390.

18 Grunwald JE, Metelitsina TI, Dupont JC, Ying GS, Maguire MG. Reduced foveolar choroidal blood flow in eyes with increasing AMD severity. Invest Ophthalmol Vis Sci 2005; 46(3): 1033-1038.

19 Metelitsina TI, Grunwald JE, DuPont JC, Ying GS. Effect of niacin on the choroidal circulation of patients with age related macular degeneration. Br J Ophthalmol 2004; 88(12): 1568-1572.

20 Metelitsina TI, Grunwald JE, DuPont JC, Ying GS. Effect of Viagra on the foveolar choroidal circulation of AMD patients. Exp Eye Res 2005; 81(2): 159-164.

21 Michels S, Hansmann F, Geitzenauer W, Schmidt-Erfurth U. Influence of treatment parameters on selectivity of verteporfin therapy. Invest Ophthalmol Vis Sci 2006; 47(1): 371-376.

22 Costa RA, Farah ME, Cardillo JA, Calucci D, Williams GA. Immediate indocyanine green angiography and optical coherence tomography evaluation after photodynamic therapy for subfoveal choroidal neovascularization. Retina 2003; 23(2): 159-165.

23 Ozdemir H, Karacorlu SA, Karacorlu M. Early optical coherence tomography changes after photodynamic therapy in patients with age-related macular degeneration. Am J Ophthalmol 2006; 141(3): 574-576. 
24 Riva CE, Harino S, Petrig BL, Shonat RD. Laser Doppler flowmetry in the optic nerve. Exp Eye Res 1992; 55(3): 499-506.

25 Uhlmann S, Friedrichs U, Eichler W, Hoffmann S, Wiedemann P. Direct measurement of VEGF-induced nitric oxide production by choroidal endothelial cells. Microvasc Res 2001; 62(2): 179-189.

26 Schmidt-Erfurth U, Schlotzer-Schrehard U, Cursiefen C, Michels S, Beckendorf A, Naumann GO. Influence of photodynamic therapy on expression of vascular endothelial growth factor (VEGF), VEGF receptor 3, and pigment epithelium-derived factor. Invest Ophthalmol Vis Sci 2003; 44(10): 4473-4480.

27 Grunwald JE, Iannaccone A, DuPont J. Effect of isosorbide mononitrate on the human optic nerve and choroidal circulations. Br J Ophthalmol 1999; 83(2): 162-167.

28 Luksch A, Polak K, Beier C, Polska E, Wolzt M, Dorner GT. Effects of systemic NO synthase inhibition on choroidal and optic nerve head blood flow in healthy subjects. Invest Ophthalmol Vis Sci 2000; 41(10): 3080-3084. 